\title{
Integrated Methodologies for the 3D Survey and the Structural Monitoring of Industrial Archaeology: The Case of the Casalecchio di Reno Sluice, Italy
}

\author{
Gabriele Bitelli, Giorgia Gatta, Valentina Alena Girelli, Luca Vittuari, \\ and Antonio Zanutta \\ Department of Civil, Environmental, and Materials Engineering (DICAM), University of Bologna, Viale del Risorgimento 2, \\ 40136 Bologna, Italy \\ Correspondence should be addressed to Gabriele Bitelli, gabriele.bitelli@unibo.it
}

Received 24 March 2011; Accepted 17 April 2011

Academic Editor: Francesco Soldovieri

Copyright (C) 2011 Gabriele Bitelli et al. This is an open access article distributed under the Creative Commons Attribution License, which permits unrestricted use, distribution, and reproduction in any medium, provided the original work is properly cited.

\begin{abstract}
The paper presents an example of integrated surveying and monitoring activities for the control of an ancient structure, the Casalecchio di Reno sluice, located near Bologna, Italy. Several geomatic techniques were applied (classical topography, high-precision spirit levelling, terrestrial laser scanning, digital close-range photogrammetry, and thermal imagery). All these measurements were put together in a unique reference system and used in order to study the stability and the movements of the structure over the period of time observed. Moreover, the metrical investigations allowed the creation of a 3D model of the structure, and the comparison between two situations, before and after the serious damages suffered by the sluice during the winter season 2008-2009. Along with the detailed investigations performed on individual portions of the structure, an analysis of the whole sluice, carried out at a regional scale, was done via the use of aerial photogrammetry, using both recently acquired images and historical photogrammetric coverage. The measurements were carried out as part of a major consolidation and restoration activity, carried out by the "Consorzio della Chiusa di Casalecchio e del Canale di Reno".
\end{abstract}

\section{Introduction}

The concept of "industrial archaeology" was introduced in 1950 in England to consider the branch of archaeology that, in synergy to engineering, architecture, and economy, studies the industrial past with the aim of documenting, protecting, and exploring the cultural heritage of industrial heritage [1]. The systematic study of this type of structures requires an integrated approach, which starts from the investigation of the historical aspects of the subject, and arrives to its complete qualitative and 3D quantitative description, even considering the characteristics of the surrounding area. From an engineering point of view, often the investigations should lead to an assessment about the danger of cracks and deformations in structures, from the viewpoint of static conditions and thus to ensure the stability, security, and the possibility of preservation over time.
In this context, the first objective of this work is to discuss - on an interesting case study-some of the possibilities provided today by engineering geomatics through the integration of different surveying techniques and methods. The case study is related to the description of high-precision surveys and metrical investigations on the main elements of the ancient sluice located in Casalecchio di Reno on the Reno river, close to Bologna, Italy (Figure 1 and Figure 2). The sluice is considered the most ancient hydraulic system still in activity in Europe and was recently included in the UNESCO list of Monuments and Sites as Messengers of Peace.

As for the geometry of the structure, it must be noted that the upper edge is not horizontal, but it shows a depressed area in order to redirect water to the hydraulic right edge of the dam, where a water deviation is performed. The length of the sluice is 160.4 meters. The highest point is located at the left edge and it rises to $0.54 \mathrm{~m}$ with respect to the most 


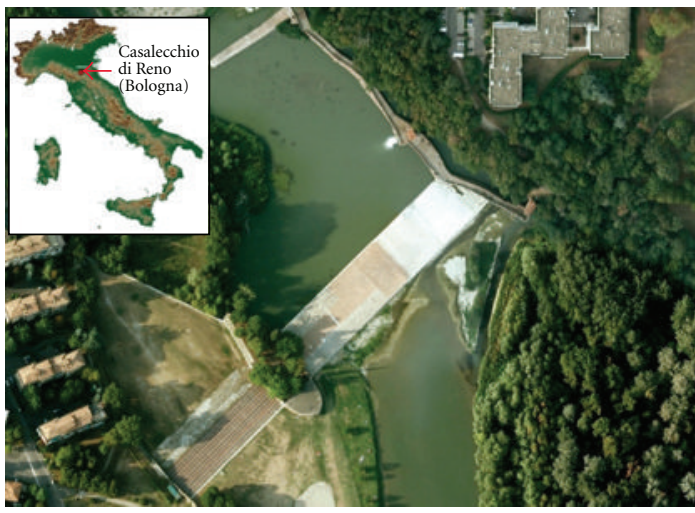

(a)

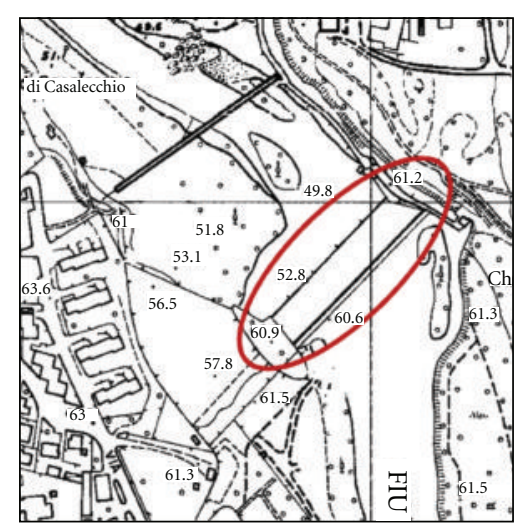

(b)

FIgURE 1: The Casalecchio di Reno sluice on high-resolution satellite image and 1:5000 technical map.

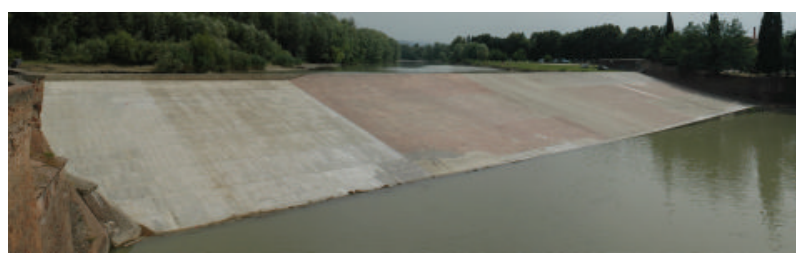

(a)

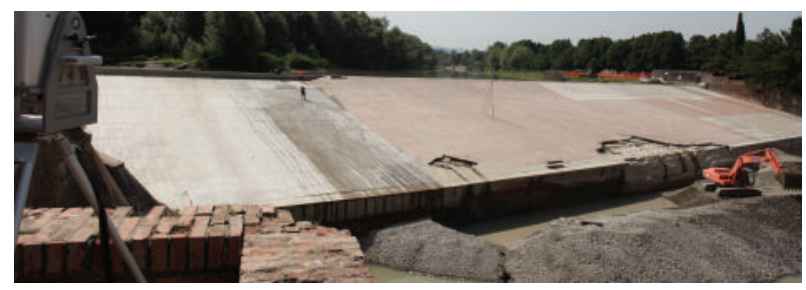

(b)

Figure 2: Images of the sluice, taken in 2005 (a) and 2009 (b); the second shows the damages suffered after the winter season 20082009.

depressed portion of the barrier, located at a distance of 71 meters from the right edge. The height difference between the upper and lower margins is $8.03 \mathrm{~m}$.

An integrated approach to the surveying problem was required to obtain a complete level of knowledge on the conditions of the structure, to be complemented by historical studies and geophysical surveys to improve the understanding of both visible and underground parts of the sluice. In a preliminary phase of the work, a contextualisation of the structure was performed, assessing its geometry and the relationship with the surrounding environment, in order to get in tune with the history of the building and to better understand its characteristics and transformations over the centuries. Subsequently, a rigorous metrical description was performed aiming at monitoring the structure and supporting the recent restoration works.

\section{Historical Notes and Geological Setting}

Water is one of the sources of civilisation, and along the history of human civilisation several solutions have been implemented to overcome water lack and increase guaranteed supply of water. Since ancient times, the idea to stop a river was developed in the arduous construction of containment barriers. These works were inspired by different needs. For example, the rudimentary wooden barriers were intended to create small reservoirs and encourage fishing. People were ingenious in the design of locks, bars, and dams with the primary intent of creating water stocks to support human life, livestock, production activities, and agriculture. Usually, actions undertaken to stop a river are technically complex and require detailed studies under the structural, hydraulic, and hydrogeological points of view. Therefore the techniques of construction of the locks were refined over time through various more or less positive experiences.

The Casalecchio di Reno sluice played in the past and still plays today a very important role for water management in the Bologna territory $[2,3]$. The first historical notes on the Casalecchio di Reno sluice are very old; they date back to the I millennium A. D. and report the news of a wooden barrage of Italy's Reno river. In this area, the Reno river shows the transition zone between the end of the mountain basin and the beginning of the valley basin [4]. The boundary between the two districts is represented by the sluice of Casalecchio and by its side spillway. In this section the Reno is of particular importance, having to fulfil the role of hydraulic connection between the Apennines and the torrential regime of a river dammed to the course of the plains. The river flows through recent wetlands and very old alluvial deposits. From a morphological point of view the area is developed between the large alluvial Apennines fans, generated by the Reno and Savena rivers, which are part of the transition zone between the northern edge of the Apennines and the alluvial plain. The entire plain near Casalecchio, extended by the river's bed to the base of the hill slopes, is identified with the southern portion of the large alluvial fan of the Reno. The structure of this fan is complex, and, proceeding northbound, the fan is expanded considerably, embracing the western suburban area of Bologna. Pulling back to the south towards the village of Sasso Marconi, it shrinks in its apical part, to progressively assume the characteristics of a typical Apennine valley. From the geological point of view, in 
the lower part of the watercourse there are alluvial soils, with extensive gravel mattresses whereas, climbing to the ridge, variously alternated limestone, sandstone, and clay can be observed; in the area characterised by gullies the presence of scaly clays prevails, while slightly further North, chalky outcrops can be observed within the Messinian evaporite rocks.

The first historic notes on the sluice date back to the I millennium A. D., then a text dated 1191 cites people called "Ramisani" as the builders of a wooden sluice for supplying mechanical energy to the mills.

In 1208 the municipality of Bologna, with a contract, acquired by the "Ramisani" the right to use excess water and made a commitment to the reconstruction and maintenance of the water lock "de lapidibus" that started in 1250 and was completed in 1278. Some operations were carried out at the beginning of the fourteenth century under the care of the Dominican and Franciscan friars. The most important ones date back to 1317 and 1324 when Cardinal Bertrando del Poggetto entrusted the Hermit Friars with the construction of a new sluice. This property was ruined after a few years for technical reasons or maybe because of the war. Ruins located downstream of the present structures can be observed today and from the remains we can assess that the artefact was made up of a conglomerate of rocks and stones tied to the bottom, with the presence of support joists which acted as the matrix. The current construction of the lock, that is in its final form, dates back to the years between 1360 and 1367 thanks to the initiative of the Papal Legate Cardinal Egidio Albornoz. In 1567, after serious damage caused by floods, the sluice was almost completely rebuilt thanks to Pope Pius V, who intervened in support of the City into financial difficulties. It was ordered that from that moment, the maintenance costs would have been supplied by all those who would have taken profit from the water. The construction of walls that held the channel from the sluice should instead go back to 1547. The work was executed by Jacopo Barozzi, known as "Vignola" (15071573). During the flood of 1617 much of the oak tables that covered the surface of the sluice were destroyed, causing even more serious damage to the walls. The restoration was undertaken under the direction of Vincenzo Sassi, and the works continued until 1627. In 1691, Domenico Guglielmi was appointed superintendent of the sluice of Casalecchio and, thanks to his experience in regulating the hydraulic systems, he performed surveys with the drawings of graphical hydraulic profiles. The extraordinary restoration of the sluice ended in the eighteenth century, and underwent routine maintenance (Figure 3).

In the next century the Reno recorded more flood events. Three of these exceeded the height of three meters to the section of Casalecchio. On the 1st of October 1893, a violent storm hit the night of the Tuscan-Emilian Apennines [5]. The Reno Valley was upset by the force of water that caused landslides and overflowing rivers. The wave of flood, with its overwhelming force, arrived in Casalecchio at ten o'clock in the morning. At eleven o'clock the hydrometer recorded the height of 4.70 meters above the lower edge of the sluice, a value never before achieved and never surpassed. During the

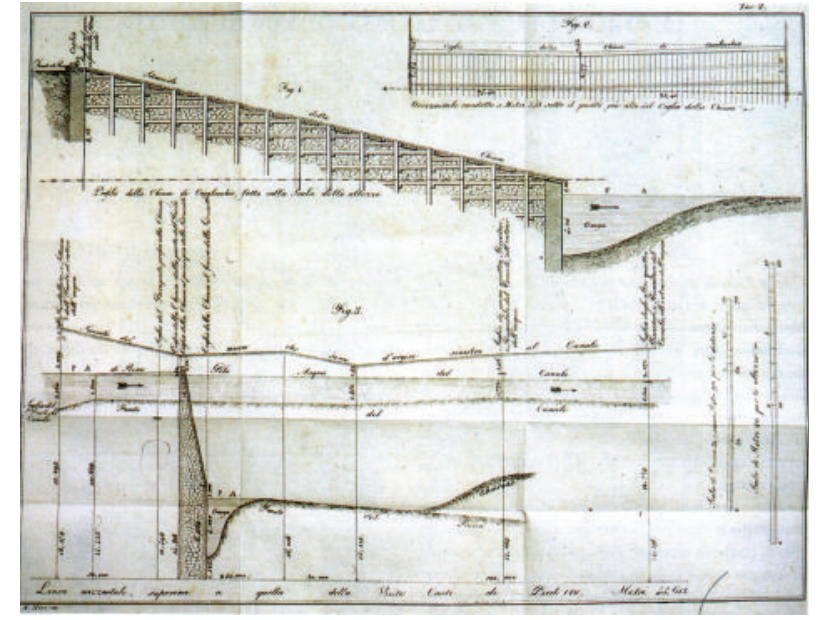

Figure 3: Sections of the Casalecchio di Reno by Antonio Lecchi, 1776.

"great flood" the structure itself did not show any structure failure or serious injury, it was bypassed by the water on the left side. The energy of the flood then poured on the wall that was already weakened by earlier events, it did not resist the pressure and collapsed. The result was a profound change of the river bed that dug a new course on the left. This caused the block of the industries in Bologna as well as its sewage and irrigation systems. Thanks to 660 workers that carried out the major works, in 1895 the complex was rebuilt in its final structure. In the new structure the slide was entirely covered with sheets of white granite with a thickness of 10-12 cm instead of the old coating made with planks of oak attached to the wall structure. In 1915 the central plank of wood was replaced with slabs of red granite. In the years 1926-27 and later in the year 1939-40 other white granite slabs on the left side structure were incorporated. The sluice was then repaired after an air force raid during the war in 1945 before replacing the last parts of the wooden table with sheets of trachyte. The complex hydraulics of the sluice is now owned by the "Consorzio della Chiusa di Casalecchio."

This institution is responsible for the management, maintenance, and enhancement of this magnificent work: the reported activities have been requested by the Consortium in the framework of this task.

\section{Materials and Methods}

The surveying activities on the sluice structure were carried out in 2005, 2006, and 2009 and involved different surveying techniques: classical topography, high-precision spirit levelling, range-based terrestrial laser scanning, digital photogrammetry, and thermal imagery.

The last measurement campaign in 2009 was mainly devoted to support the restoration activities, carried out after the severe damages suffered by the lowest part of the sluice structure during the 2008-2009 winter (Figure 2).

The whole set of activities, methods, and measures were planned in order to allow an effective integration 
between the various techniques chosen on the basis of their respective potential. Regarding the horizontal and vertical reference systems, the main work was carried out on a local system, but the availability in the same area of a GPS point already established by the University of Bologna for regional subsidence monitoring, and of a benchmark from an important district levelling network, permits to move all the results in absolute system when necessary.

\section{High-Precision Three-Dimensional Topographic Surveys}

In 2005, a three-dimensional network has been installed on the sluice to achieve high-precision three-dimensional measurements using highly accurate engineering total stations (Figure 4). The network was surveyed in 2005, 2006, and 2009; in the last campaign, five points in the lower border of the slide were lost due to the damages occurred in the 20082009 winter.

The control network consisted of 11 self-centering devices on the slide, anchored to the structure below the slabs, and used for the positioning of the retroreflective prisms and also of the reference targets used in the laser scans. Moreover, 22 additional points were identified, already present in the structure, that were used also as reference benchmarks for the high-precision geometric levelling.

From two positions located outside the structure of the dam, the measurements were carried out using highprecision Leica total stations (TCA2003 and TC2003 in 2005-2006, two TCA2003 in 2009), characterised by an angular accuracy of $0.5^{\prime \prime}$ and a nominal precision of $1 \mathrm{~mm}+1 \mathrm{ppm}$ for the distances. The total stations were equipped with dual-axis compensators, which compensate the horizontal and vertical readings for small deviations of the principal axes with respect to the vertical line; the robotic station Leica TCA2003 is able to automatically recognize the centre of the targets.

The atmospheric refraction was modelled from the measurements of air temperatures, barometric pressure levels, and relative humidity recorded during the measurements on both sides of the structure. In fact, knowledge of the refractive index $(n)$ of the prevailing atmosphere is necessary in order to apply a correction for velocity to the measured distance; the classical approach described by [6], subsequently adapted considering wavelengths between 560 and $900 \mathrm{~nm}$, was adopted.

A rigorous least squares adjustment of the dataset was carried out adopting a redundant number of measurements, but using minimum constraints to define the reference system; in this way the coordinates of all control points were computed. Regarding the precision of the surveys, for the 11 points along the chute the major semiaxis of the associated error ellipses at 95\% probability level reached maximum values on the order of $2.5 \mathrm{~mm}$ whilst worse results were obtained for the other points not characterised by self-centring devices. The comparison between subsequent campaigns (2005 versus 2006, 2009 versus 2006), taking into account the confidence intervals associated to the coordinates, has generally shown nonsignificant planimetric movements for the structure.

\section{Differential Levelling}

Aiming at detecting high-precision estimates of elevation changes, annual spirit levelling surveys have been performed by means of high-accuracy digital levels.

Due to the impossibility, for logistics problems, to realize specific benchmarks along the superior and inferior borders of the sluice, a network of 25 benchmarks, mainly defined by small holes along the borders (on steel joints or on stones), was established in 2005. The height origin was benchmark 21 located on the top boundary of the sluice (Figure 4(b)).

The levelling measurements have been carried out with a classical scheme using two invar staffs and by interconnected closed rings to achieve redundant data. The benchmark heights coming from the statistical analysis of the observations (adjustment computation), have been characterised by a precision to a tenth of a millimetre. The difference in elevation between surveys were in the order of the standard deviation associated to the adjusted heights, proving that the main structure did not suffer significant movements, with the exception of the points located in the inferior border near the damaged zone, where uplift movements in the order of $1 \mathrm{~mm}$ were detected (Figure 5(b)).

\section{Terrestrial Laser Scanning Surveys, Digital Photogrammetry, and Thermal Surveys}

High-density three-dimensional point clouds have been surveyed by means of terrestrial laser scanner (TLS) and integration with digital photogrammetry [7].

The first laser scanner survey of the sluice and the surrounding area has been generated in 2006 by using a Riegl LMSZ-420i instrument whilst a second survey was carried out in 2009 using a Riegl LMS-Z390; the declared precision of the two TLS instruments is, respectively, $4 \mathrm{~mm}$ (averaged) and $2 \mathrm{~mm}$. It must be noticed that in the last survey, the lower part of the structure was visible, since the water supply was interrupted by a detour. The laser scanners were coupled with calibrated Nikon D70 and Nikon D200 digital cameras [8]. The average density of point clouds was in the order of $5 \mathrm{~cm}$ on the slide, and it was increased in particular in the damaged area, located on the bottom right side of the structure (Figure 6).

To cover up the entire surface, point clouds have been acquired from four different standing points around the structure, for a total number of more than 10 millions of points.

The presence of water at the bottom of the sluice and the particular flat shape of the structure needed an accurate procedure of data processing. As a matter of fact the water surface has been the source of disturbance that locally affected the quality of the laser measurements. The relative incidence angle of the laser ray, in respect to the air-water separation surface, led in some parts to the achievement of Brewster angle limit with completely wrong points, acquired by the laser through a specular reflection of the sluice 


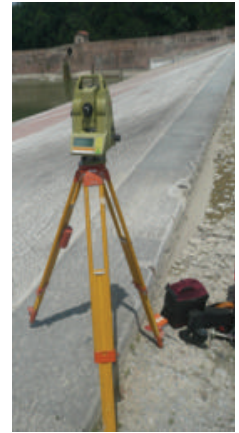

(a)

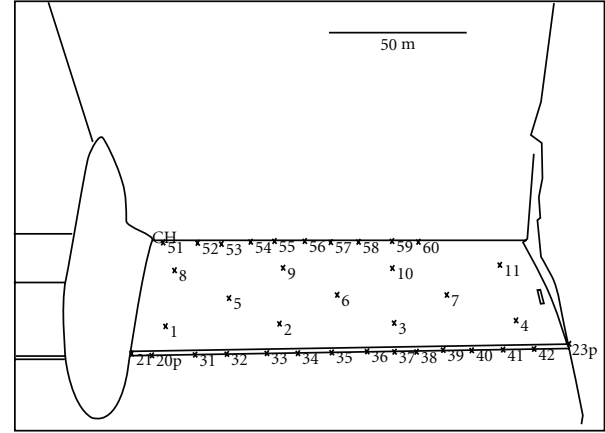

(b)

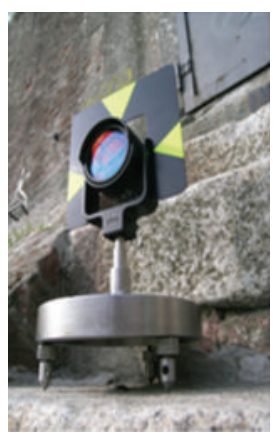

(c)

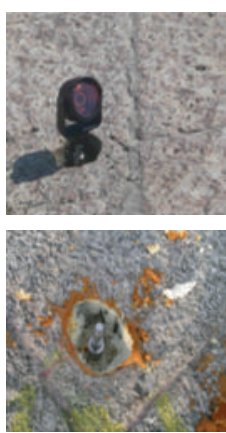

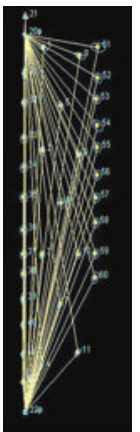

(d)

FIgURE 4: Classical topographic surveying: (a) total station; (b) scheme of control points distribution; (c) examples of GCPs characterised by forced centering devices (outside the structure and on the slide, resp.) measured using prisms; (d) map of the 3D adjusted network.

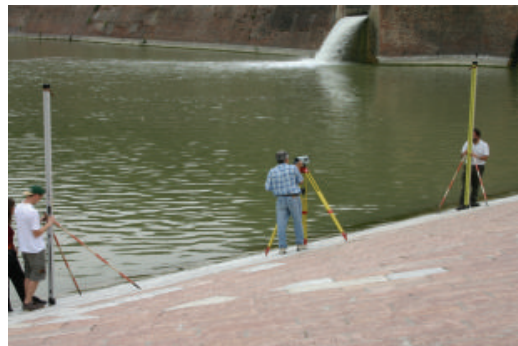

(a)

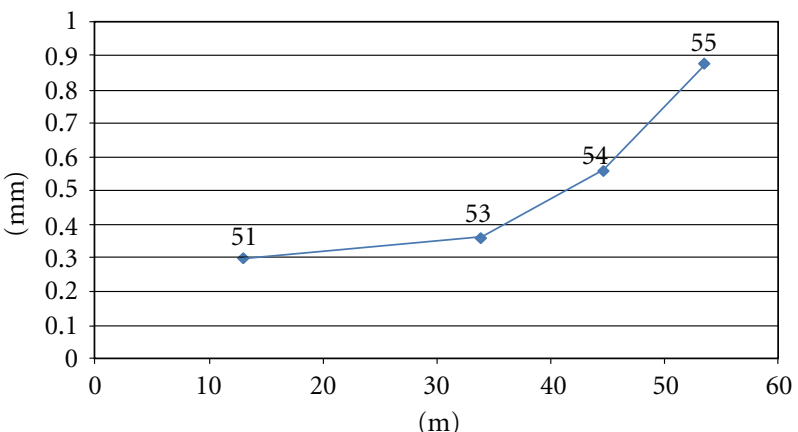

(b)

FiguRE 5: Field operations of high-precision spirit leveling (a); vertical displacements concerning the 2006-2009 time span for four benchmarks located on the bottom of the slide near the damaged zone (b).

structures (Figure 7); in this case the mirror was accidentally realised by the water surface itself. These points have been eliminated by appropriate filtering.

The flat and gently sloping surface of the chute, together with really small incidence angles, from the stations on the bottom, produced a surface affected by an unreal roughness and unexpected outliers which have been reduced by means of smoothing and filtering procedure. In this situation it must be considered that the laser footprint is very elongated, affecting the precision of the measured point.

After the postprocessing phases of laser data (filtering, merging, decimation, etc.) the point clouds have been triangulated, forming a continuous digital surface model (DSM) by means of interpolation algorithms.

The images collected with the calibrated digital camera supplied - through a postprocess-a textured representation of the three-dimensional surface models and the true orthophoto mosaics.

The resulting products of the laser surveys have been clouds of three-dimensional points referred to the same local reference system. The registration of the multiple scans has been performed using dedicated cylindrical retroreflectors placed inside the chute plan, using the same self-centring devices adopted for the planimetric survey. By so doing also the laser scanner data were referred to the same system of the other data.
During 2009, the sluice has been furthermore surveyed by means of a thermal camera, in order to investigate the capability of metrical use of thermal images.

The test has been performed by means of an NEC Thermo Tracer 9100 Pro, characterised by a single spectral band in the $8-14 \mu \mathrm{m}$ interval, a sensitivity of $0.08 \mathrm{~K}$ and a field of view ranging from $16^{\circ}$ to $21^{\circ}$. The camera is characterised by an uncooled focal plane array detector, 320 $\times 240$ pixels.

The thermographic camera detects radiation in the thermal infrared range of the electromagnetic spectrum and produces images of that radiation which could be used in the same way as conventional photogrammetric images. The main problem for integrating these data with the other is the geometric calibration of the camera, and the stability of the geometry along the images sequences. Once these problems are solved, these low-resolution thermal images can be used also for a variety of metrical-based applications [9].

Three coverage strips of the sluice have been collected trying to cover the entire structure from different points of view.

In order to dispose of a large set of visible ground control points either for exterior and interior orientation, a dense three-dimensional model of the sluice coming from the terrestrial laser scanning survey was used, recognising on the model the control points needed; a field calibration 


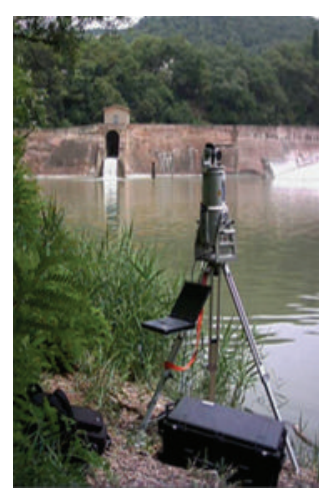

(a)

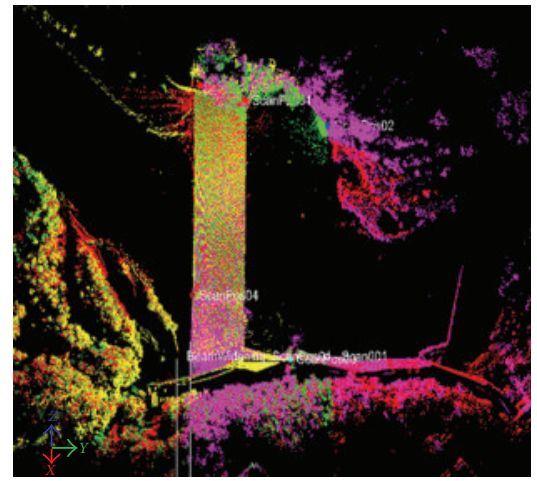

(c)

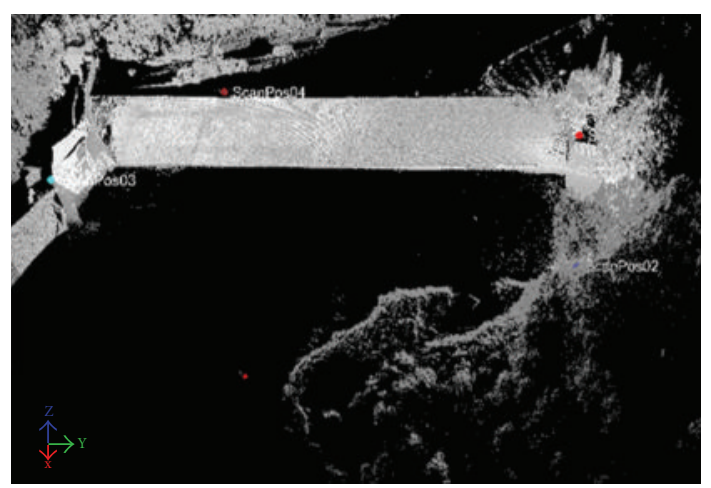

(b)

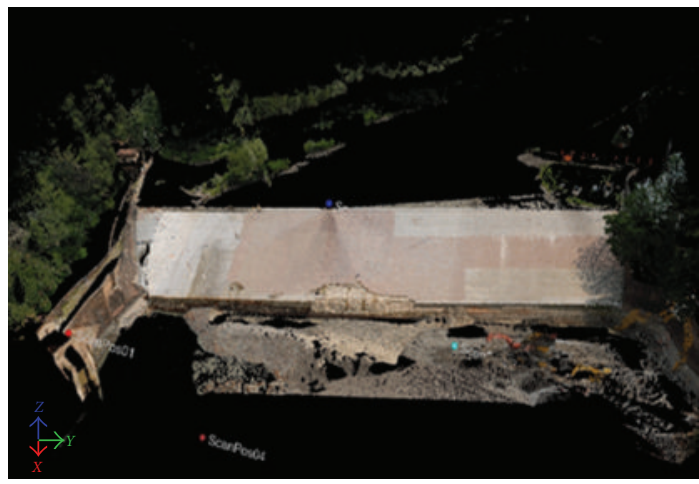

(d)

Figure 6: Terrestrial laser scanning surveys and digital photogrammetry: (a) Riegl LMSZ420i coupled with Nikon D200 digital camera; (b, c) laser scanning points clouds of the sluice and the surrounding area (2006); (d) the 3D raster model of the chute after the great damages suffered by the structure during the 2008-2009 winter.

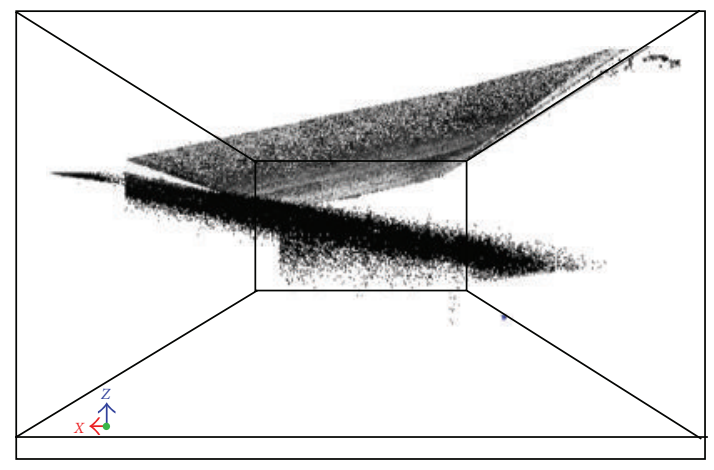

FIGURE 7: Vertical section, showing in the lower part of the points cloud the wrong points generated by a specular effect due to the achievement of Brewster angle by the incident laser ray in respect to the water surface.

procedure was experimented to estimate the intrinsic internal parameters of the camera and the external parameters of the images.

The results of camera calibration showed high distortion values, and large shifts of the principal point, but allowed to create three-dimensional raster models and thermal orthophotos of the sluice. These documents (after considering emissivity of the materials) provide temperature distribution on the structure and this information could be used to better assess the lack of homogeneity in the surface of the slide (Figure 8).

\section{Aerial Photogrammetric Processing}

In an effort to provide a geographic database covering the whole area and referring also to the changes that occurred in the recent past, a photogrammetric analysis was performed by means of the processing of aerial images acquired in different periods, starting from 1971. These data can be inserted in a dedicated GIS developed to store all the geographical data collected in the past and in the recent surveys concerning the sluice.

The example considered refers to a stereocouple at photographic scale 1:13000 from 1976 that has been scanned at 1200 dpi resolution and calibrated using an analytical procedure.

To solve the orientation problem and reconstruct the absolute geometric relationships among the images, 12 GCPs have been adopted coming from 1:5000 cartographic representations of the area (CTR 220120), after a careful analysis in order to retrieve points available also in the historical images.

A $2 \times 2 \mathrm{~m}$ grid DTM of the area has been generated automatically, by Leica Photogrammetric Suite software, 


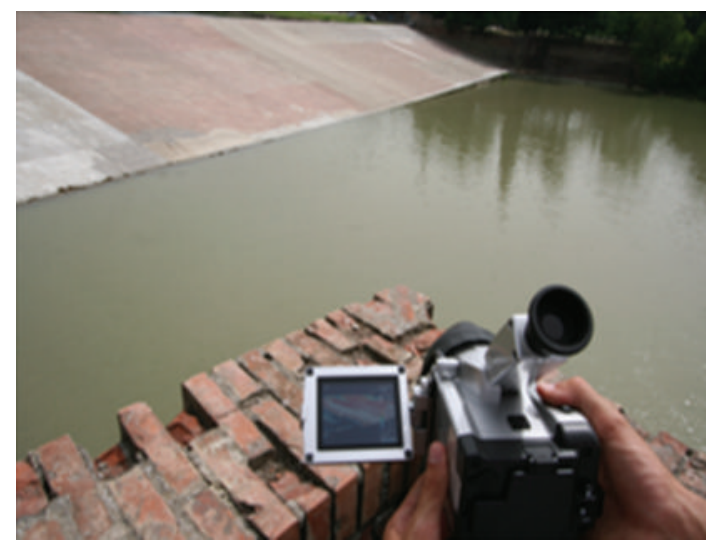

(a)

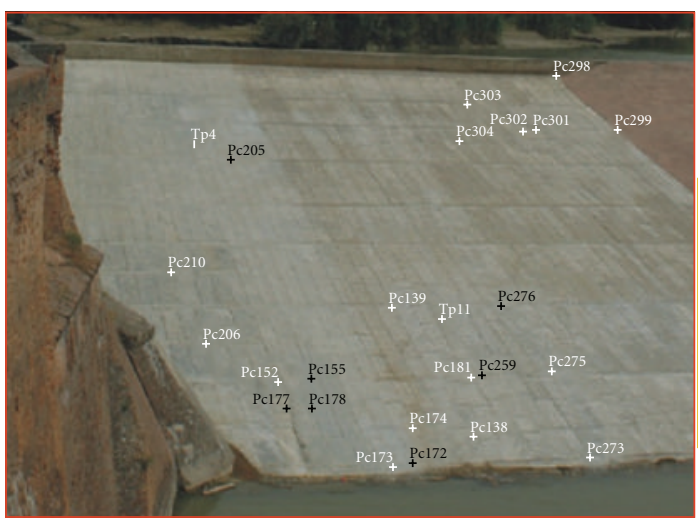

(c)

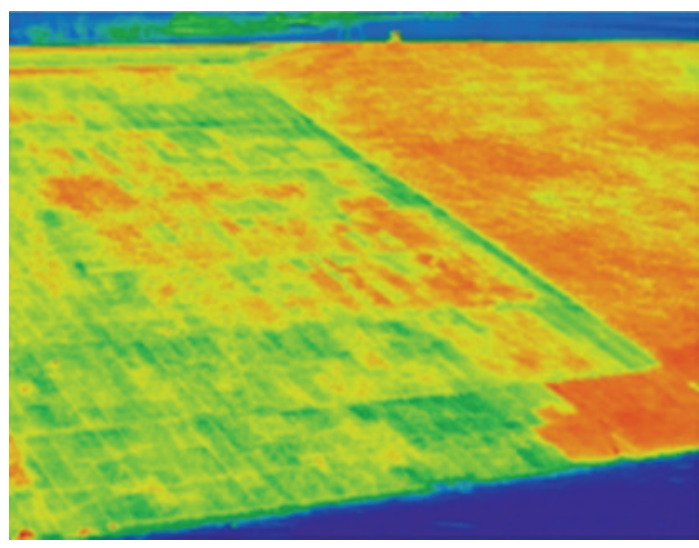

(b)

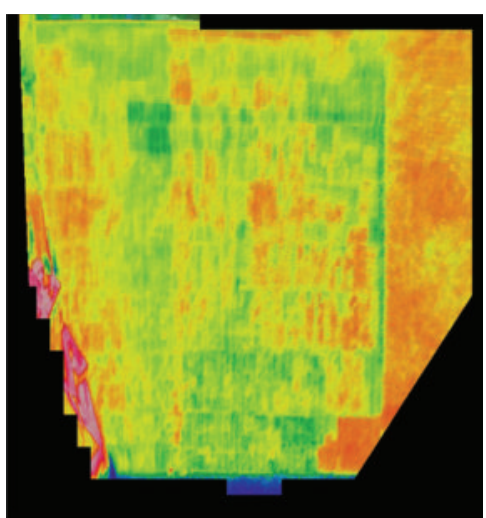

(d)

FIguRE 8: Thermal imagery: (a) NEC TH9100 PRO $320 \times 240$ thermal camera; (b) an example of thermal image characterised by $5 \mathrm{~cm}$ pixel on the object; (c) each thermal image has been calibrated by photogrammetric procedures and oriented in the space by means of the dense clouds of laser points; (d) the thermal orthophoto of a portion of the slide showing the blocks of different material related to different restoration activities carried out in the past.

with manual postediting to correct errors deriving from the image matching technique. The editing procedure consisted of manual insertion of breaklines into incorrect zones, with consequent local recalculation of the surface area.

Starting from the DSM, an orthophoto of the area characterized by a ground pixel size of $0.5 \mathrm{~m}$ has been produced and finally superimposed on the existing vector map (Figure 9).

\section{Results and Discussion}

This methodological work was initiated as part of an interdisciplinary project, created to better understand the functions of ancient structures, and as support for restoration activities. The purpose of metrical investigations was twofold: to have a detailed geometric description of the structure in order to highlight the required actions and to get evidence about movements within the structures. The comparison between the results obtained in 2005-2006 and those reached in 2009 from all the activities undertaken (three-dimensional topographic surveys, analysis of geometric surface patterns produced by repeated series of laser scanner data) has allowed us to have information about the extent of the damaged sectors and the description of movements in progress. The study of the movements undertaken within the chute of the sluice showed no significant changes between the positions of control points. The absence of differential movements is an indicator of good health in the structure of the dam itself.

Nevertheless spirit levelling surveys have pointed out some significant changes at the border.

The main differences concerned the damaged area of the sluice destroyed after an exceptional atmospheric event registered during the 2009 winter. The strong rains and floods have caused the destruction of some benchmarks and the removal of large stone blocks located at the bottom of the sluice.

The high-density multitemporal DSMs generated by means of TLS have been registered in one reference system thanks to the presence of GCPs available on the sluice. From the comparison of the surfaces some significant differences have been evaluated (Figure 10).

\section{Conclusions}

The city of Bologna, with an advance of more than three centuries, prefigures the production model known as the "First Industrial Revolution" thanks to the Sluice of Casalecchio 


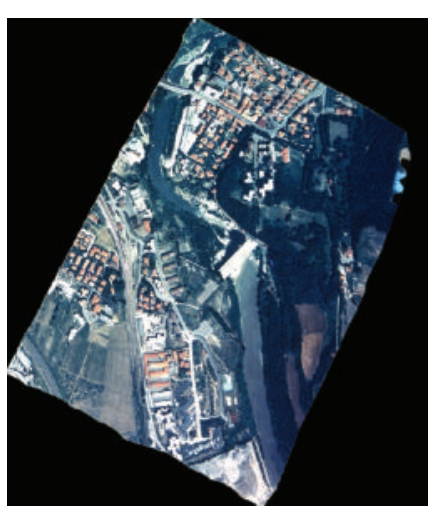

(a)

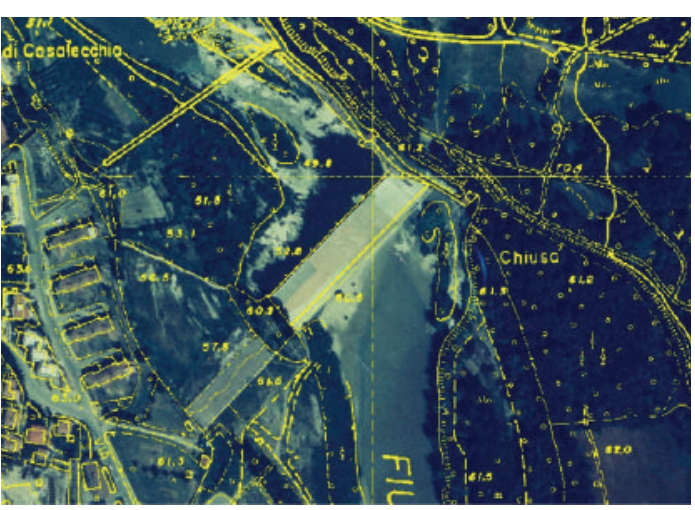

(b)

FIgURE 9: The orthophoto (a) and the superimposition of vector map on a detail related to the sluice area (b).

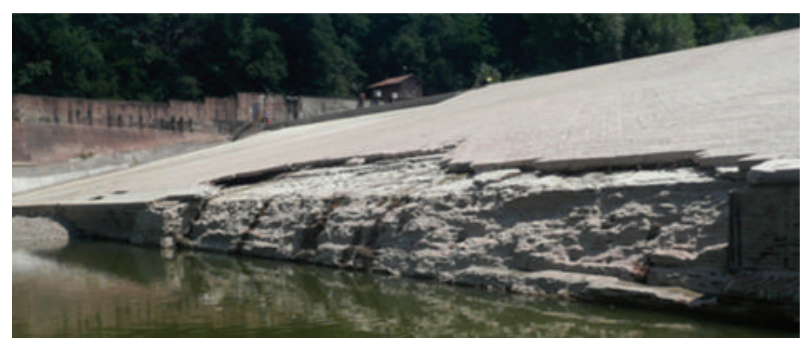

(a)

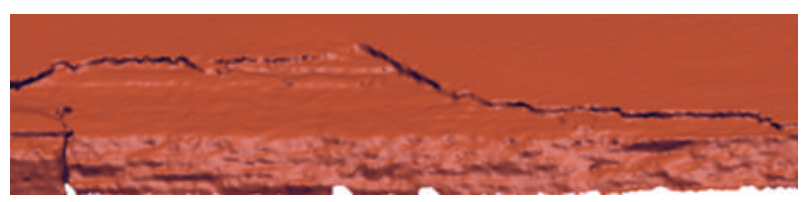

(b)

Figure 10: Detail of the damaged area at the bottom of the sluice (2009) before restoration: (a) RGB image; (b) TLS 3D raster model.

which can be considered as a symbol of this new economic model.

Due the importance of this hydraulic structure, the public owners always demonstrated care and periodical restoration works have been performed.

Starting from 2005 a multidisciplinary project concerning the full study of the sluice took place. As a result of the geomatic surveys performed, a 3D model of the structure has been generated. Concerning the monitoring of the stability of the sluice by means of topographic methods, no significant displacements have been detected (exceptions are represented by a few benchmarks located on the bottom of the structure, close to the damaged zone). These results confirm the good health of the old structure.

\section{Acknowledgments}

The authors want to acknowledge the "Consorzio della Chiusa di Casalecchio e del Canale di Reno," in particular F. Marchi, for allowing the possibility to realize this work, and A. Raffagli, responsible for the structural works. Thanks also to C. Bonini, G. Capone, D. Garbellini, F. Girardi, E. Mandanici, M. Mannina, B. Roffarè, and M. A. Tini, for the collaboration in different phases of the surveys.

\section{References}

[1] N. Cossons, Ed., Perspectives on Industrial Archaeology, London Science Museum, 2000.

[2] F. Maranesi, F. Marchi, M. Poli, and G. Tabarroni, Le Acque a Bologna, Editrice Compositori, Bologna, Italy, 2005.

[3] A. Zanotti, Il Sistema delle Acque a Bologna dal XIII al XIX Secolo, Editrice Compositori, Bologna, Italy, 2000.

[4] A. Papetti, Casalecchio di Reno, Aspetti Idrogeologici del Territorio, Telesio Editrice, Milano, Italy, 2003.

[5] U. Brunelli and F. Canonici, La Chiusa di Casalecchio e i Lavori Eseguiti dalla Provincia di Bologna per la Chiusura della Rotta di Reno in Sinistra Avvenuta il $1^{\circ}$ Ottobre 1893 e per la Sistemazione del Fiume a monte della Chiusa, Regia Tipografia, Bologna, Italy, 1896.

[6] H. Barrell and J. E. Sears, "The Refraction and dispersion of air for visible spectrum," Philosophical Transactions of the Royal Society of London. Series A, vol. 238, pp. 1-64, 1939.

[7] K. Kraus, Photogrammetry-Geometry from Images and Laser Scans, De Gruyter, Berlin, Germany, 2007.

[8] T. Luhmann, S. Robson, S. Kyle, and I. Harley, Close Range Photogrammetry, Whittles, 2006.

[9] H. Kaplan, Practical Applications of Infrared Thermal Sensing and Image Equipment, SPIE, 2007. 

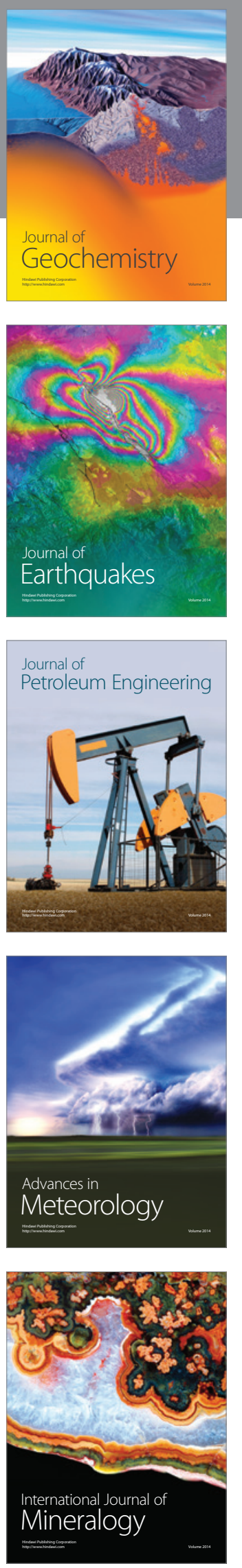
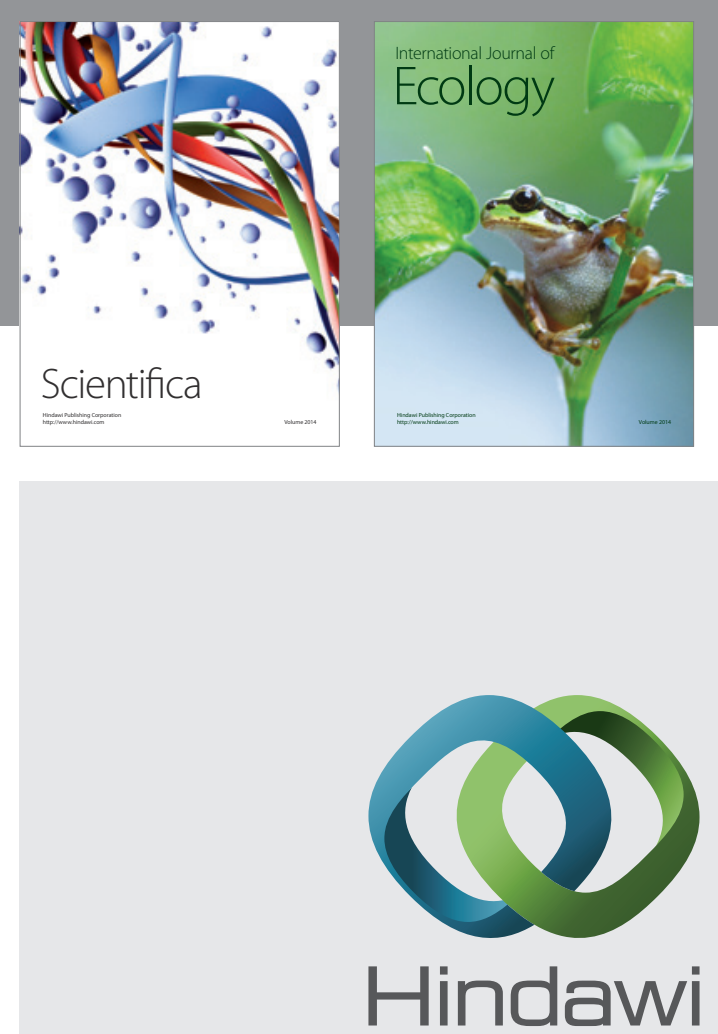

Submit your manuscripts at http://www.hindawi.com
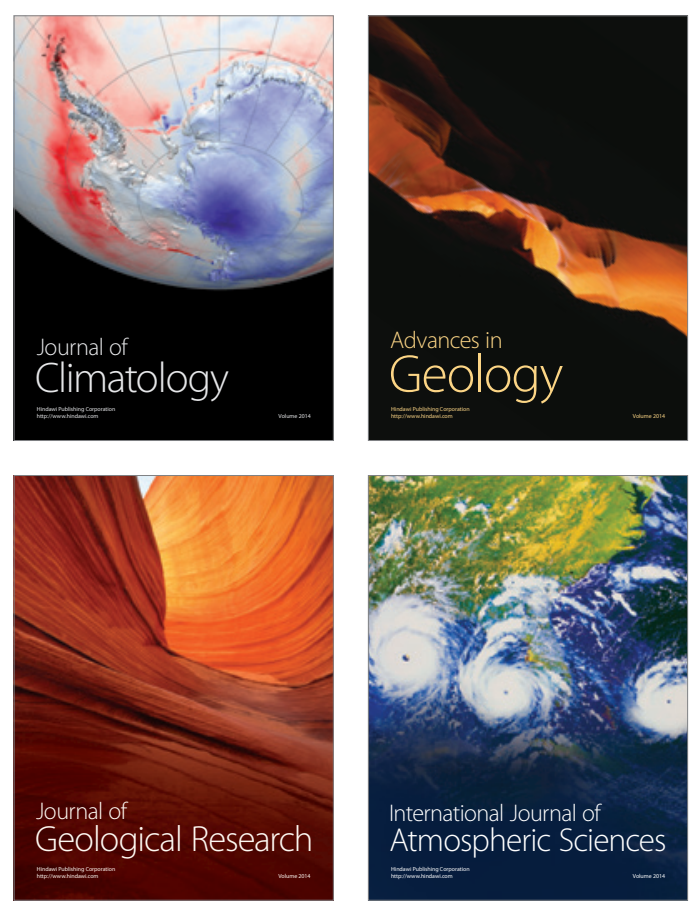
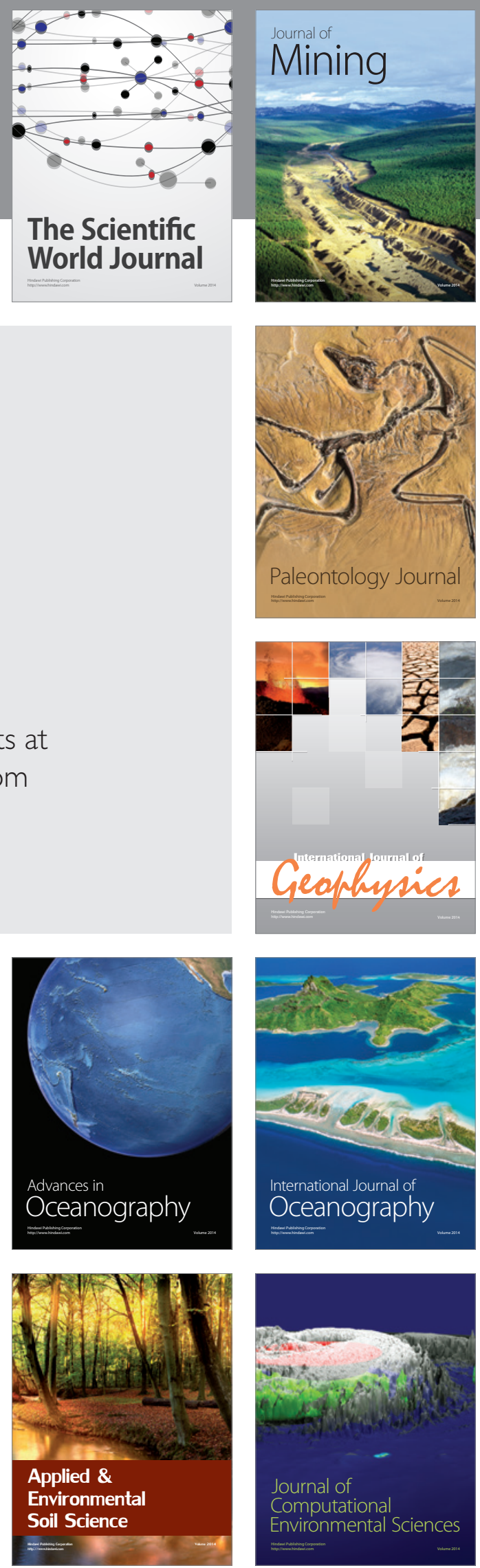